\title{
Development of a population suppression strain of the human malaria vector mosquito, Anopheles stephensi
}

\author{
Osvaldo Marinotti ${ }^{1}$, Nijole Jasinskiene ${ }^{1}$, Aniko Fazekas ${ }^{1}$, Sarah Scaife ${ }^{2}$, Guoliang Fu ${ }^{2}$, Stefanie T Mattingly ${ }^{1}$, \\ Karissa Chow ${ }^{1}$, David M Brown ${ }^{3}$, Luke Alphey ${ }^{2,4}$ and Anthony A James ${ }^{1,3^{*}}$
}

\begin{abstract}
Background: Transgenic mosquito strains are being developed to contribute to the control of dengue and malaria transmission. One approach uses genetic manipulation to confer conditional, female-specific dominant lethality phenotypes. Engineering of a female-specific flightless phenotype provides a sexing mechanism essential for male-only mosquito, release approaches that result in population suppression of target vector species.

Methods: An approach that uses a female-specific gene promoter and antibiotic-repressible lethal factor to produce a sex-specific flightless phenotype was adapted to the human malaria vector, Anopheles stephensi. Transposon- and site-specific recombination-mediated technologies were used to generate a number of transgenic An. stephensi lines that when combined through mating produced the phenotype of flight-inhibited females and flight-capable males.
\end{abstract}

Results: The data shown here demonstrate the successful engineering of a female-specific flightless phenotype in a malaria vector. The flightless phenotype was repressible by the addition of tetracycline to the larval diet. This conditional phenotype allows the rearing of the strains under routine laboratory conditions. The minimal level of tetracycline that rescues the flightless phenotype is higher than that found as an environmental contaminant in circumstances where there is intensive use of antibiotics.

Conclusions: These studies support the further development of flightless female technology for applications in malaria control programmes that target the vectors.

Keywords: Anopheles stephensi, Transgenic mosquitoes, Malaria

\section{Background}

Methods are being developed to control transmission of vector-borne diseases based on transgenic mosquitoes carrying a conditional dominant lethal gene (release of insects carrying a dominant lethal [RIDL]) [1-5]. The principal dengue virus vector, Aedes aegypti, was engineered in one RIDL-based approach to carry a transgene conferring a repressible female-specific flightless phenotype (fsRIDL) [2]. The sex-specificity of the phenotype results from the

\footnotetext{
* Correspondence: aajames@uci.edu

'Department of Molecular Biology \& Biochemistry, University of California, Irvine, CA, 92697-3900, USA

${ }^{3}$ Departments of Microbiology \& Molecular Genetics and Molecular Biology \& Biochemistry, 3205 McGaugh Hall, University of California, Irvine, CA,

92697-3900, USA

Full list of author information is available at the end of the article
}

regulatory DNA of the Ae. aegypti gene, Ae. aegypti Actin$4[2,6]$, that encodes a female-specific flight muscle protein. These strains are showing promising results in meeting the goal of new tools for dengue vector population suppression although further refinements are necessary $[7,8]$. The technology also was shown to work in a related species, Aedes albopictus [4]. The technological advances achieved with Aedes species are potentially applicable to anophelines that transmit malaria parasites.

Features that contribute to the suitability of an fsRIDLbased, population-suppression tool for controlling malaria transmission include that the vector species is the major one responsible for malaria transmission in a defined geographical region and that controlling transmission will have a meaningful impact on local disease incidence and

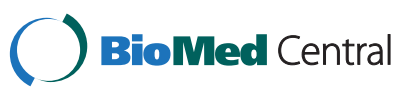


prevalence. In addition, the efficacy of such tools would be supplemented if the proposed species were endemic to a country that had in place robust malaria control programmes with which to interact and the target areas were of a reasonable scale. Geographic and ecological islands represented by confined urban and semi-urban areas would be ideal for evaluating the impact of the population suppression strain on the target species. Malaria transmission by Anopheles stephensi in urban and peri-urban settings in the Indian subcontinent appears to meet these criteria [9-11]. Malaria is endemic to the Indian subcontinent where 70-100 million cases per year are reported [12]. Successful application of moleculargenetic approaches to controlling malaria transmission by An. stephensi is expected to have a major effect on the disease burden of one of the most populous places in the world. Anopheles stephensi is recognized as having two forms that may be isolated reproductively and a third intermediate form $[13,14]$. The type-form is found principally in urban areas where it is responsible for the majority, if not all, of malaria transmission that occurs in cities. It breeds in peridomestic water containers and is highly anthropophilic. Distribution and feeding habits create functional "genetic islands" defined by breeding sites and hosts. A rural form, 'mysorensis', is found in the arid countryside and is not a major vector of malaria. The role of the intermediate form in transmission is unclear. Therefore, the urban mosquitoes are good targets for an fsRIDL-based, population-suppression tool.

The data presented here demonstrate that it is possible to engineer An. stephensi with a repressible female-specific flightless phenotype based on the use of the female-specific flight muscle promoter. These results support the prospect of applying fsRIDL in the fight against malaria on the Indian subcontinent.

\section{Methods \\ Mosquito rearing}

A colony of An. stephensi (gift of M Jacobs-Lorena, Johns Hopkins University) bred at the UCI insectary for longer than five years was used in the experiments. Insects were maintained at $27^{\circ} \mathrm{C}$ with $77 \%$ humidity and $12 \mathrm{hr}$ day/ night, 30 min dusk/dawn lighting cycle. Larvae were fed a diet of powdered fish food (Tetramin) mixed with yeast. Adults were provided ad libitum with a $0.3 \mathrm{M}$ sucrose solution in water and anesthetized mice were used for blood feeding when required. The blood-feeding protocol was approved by the Institutional Animal Care and Use Committee of the University of California, Irvine (NIH Animal Welfare Assurance number: A3416.01; approved February 20, 2008), Protocol Number: 1998-1411 (approved May 17, 2012). Transgenic and control non-transgenic (wildtype) mosquitoes were reared using the same standardized insectary procedures, unless otherwise indicated.

\section{Identification of the Aedes aegypti Actin-4 gene orthologue in Anopheles stephensi}

Primary nucleotide sequences of the Ae aegypti Actin-4. (AeAct-4, AY531222) gene were used to search Vectorbase [15] for an orthologue in the genome and transcriptome of An. stephensi. The lowest e-value and highest score were assigned to ASTM009772. The reciprocal best BLAST hit strategy supports the 1:1 orthology of AeAct-4. and ASTM009772. ASTM009772 is designated hereafter as AsAct-4.

Total RNA samples extracted with TRIZOL from larvae (mixed sexes), and separately from males and females, pupae and adults were treated with RNAse-free DNAse and served as templates for Reverse Transcriptase-PCRs, using a gene-specific pair of primers complementary to sequences located in the first and second exons of ASTM009772 (AsActin4 exon1for 5'-CACATAGTTGT TAGCTGGGAGAGC-3', and AsActin4 5RACE 5' -CAG ATCCATACGCAGGATAGCATG-3').

The transcription start-site and intron location of AsAct4 was identified by 5 'RACE and RT-PCR techniques. 5' RACE was performed using the Ambion FirstChoice RLM-RACE kit using the gene-specific primer AsActin45RACE. Comparison of cDNA (5'RACE and RT-PCR products) and An. stephensi genomic DNA, scaffold 01062 [15] sequences revealed one intron in the 5'UTR.

\section{Mosquito transgenesis, embryo microinjection and Southern-blot hybridization analyses}

Microinjection of the pBac-IE1-DsRed2-AeAct4-tTA driver construct (OX3545) [2] with the piggyBac helper plasmid [16] in An. stephensi embryos was performed as described previously [17]. OX3545 contains the AeAct-4 promoter and first intron cloned at the $5^{\prime}$ end of tTAV linked to a SV40 3' UTR, as described previously [2]. This gene cassette was inserted into a piggyBac vector containing the Hr5-IE1 promoter driving a gene encoding the fluorescent protein DsRed, to facilitate identification of transgenic mosquitoes. The helper plasmid phsp-pBac [16] has DNA sequences that drive constitutive expression of functional piggyBac transposase that catalyzes random insertions of the driver construct into the mosquito genome.

Each $G_{0}$ male was mated with fifteen virgin females and groups of ten $G_{0}$ females were mated with five males. The $G_{1}$ progeny and the subsequent generations were screened at the larval stage with fluorescence microscopy for the expression of the DsRed marker gene. Transgenic lines were maintained as hemizygous by out-crossing transgenic individuals at every generation with wild-type mosquitoes. Southern blotting and hybridization techniques were used to detect transgene integration and copy number. Genomic DNA extracted from groups of six transgenic or wild-type control females was fractionated by agarose gel electrophoresis and transferred to Zeta-probe GT 
Genomic Tested Blotting Membranes (Bio-Rad, Hercules, CA) as described previously [18] and using standard protocols [19]. The probe used to identify transgene integrations consisted of the DsRed2 ORF and was amplified from the OX3545 plasmid using the primers $5^{\prime}$-GCAGC TGATCACGTACGCTC-3' and 5'-GTGCGCTCGTACT GCTCCAC-3' and labelled with ${ }^{32} \mathrm{P}$ using the Megaprime DNA labelling system (Amersham).

The AsAct-4 promoter and 5'UTR were used to make the driver construct, pBac-IE1-DsRed2-AsAct4-tTA (AsOX3545). A DNA fragment including 1014 base pairs (bp) of the $5^{\prime}$-end gene sequence, the first exon (96 bp), and the complete intron (271 bp) was amplified with the primers AsPforEcoRV (5'-GATATCCGAGTAGTGGGT GCTACTGTAGCG-3') and AsPrevSpeI (5'-ACTAGTG CCGAGTGTTATGGATTGTCCTGCAGG-3'). The amplified DNA was digested with EcoRV and SpeI restriction endonucleases and the resulting fragment cloned into OX3545 digested previously with NruI and SpeI. Microinjection of AsOX3545 in An. stephensi embryos and analyses of the resulting transgenic lines were performed as described above.

The effector construct attB-3×P3-DsRed2-tetO-Nipp1Dm (OX3547) [2] was injected into embryos of the docking-site strain, attP43 [20] together with in vitro-transcribed $\phi C 31$ integrase mRNA [21]. The $\phi C 31$ integrase catalyses recombination between the $a t t B$ site in the plasmid and the attP site in the genome of the docking site strain, promoting sitespecific integration of transgenes in the target genome. OX3547 contains the regulatory sequence of a tetracycline responsive element (tRE), comprising multiple copies of the tetO sequence, to which tTA binds, and a basal promoter driving expression of the effector molecule, Nuclear Inhibitor of PP1 (Nipp1Dm). Nipp1Dm overexpression induces phenotypes that include lethality, abnormal mitotic figures and defects in muscle development [2,22,23]. tTA cannot bind to tetO in the presence of tetracycline and expression of Nipp1Dm remains uninduced.

The survivors of OX3547 injections were grouped into female and male pools and out-crossed with wild-type, non-transgenic mosquitoes of the opposite sex. The offspring were screened as larvae with fluorescence microscopy for the expression of the fluorescent DsRed marker. Genomic DNA extracted from groups of six females was fractionated by agarose gel electrophoresis and transferred to Zeta-probe GT Genomic Tested Blotting Membranes (Bio-Rad, Hercules, CA). Southern blots to evidence transgene integration were performed as described above and used the same ${ }^{32}$ P-labelled DsRed2 ORF probe.

\section{Generation of conditional flightless mosquitoes and tetracycline rescue of the phenotype}

Conditional flightless female mosquitoes were generated by crossing males or females hemizygous for the driver constructs with those of the opposite sex hemizygous for the effector construct. Progeny were screened as larvae with fluorescence microscopy for the expression of the marker genes. The DsRed2-encoding marker gene is the same in the driver and effector lines, however the driver lines express red fluorescent protein in a scattered pattern throughout the body under the control of the IE1 promoter while DsRed2 expression in the effector lines is driven by the eye-specific promoter, $3 \times \mathrm{P} 3$. Progeny of crosses of the driver and effector lines presenting both the IE1 and the $3 \times \mathrm{P} 3$ driven fluorescence patterns were selected for further analyses. The double-hemizygous individuals were raised to adults and the survival of males and females as well as frequency of adult flightless phenotype scored. Adult females were considered flightless when they could not elevate and remain aloft after the mosquito cages were agitated. Flightless females tend to walk, may be able to hop but do not fly for even short distances. Alternatively, double-hemizygous progeny were raised in the presence of tetracycline added to the water during larval development. Adults were offered a $0.3 \mathrm{M}$ sucrose solution supplemented with tetracycline (the same concentration used for rearing larvae) and allowed to feed ad libitum. The survival of tetracyclinetreated males and females, and frequencies of marker gene and adult flightless phenotypes were scored.

\section{Results}

\section{Transgene constructions}

Two existing transgene constructs, previously used for genetic transformation of Ae. aegypti, and a third, novel construct were used in the experiments (Figure 1). Replacement of the AeAct-4 gene 5-end sequence (putative promoter and first intron) with the orthologous DNA from AsAct-4 originated the novel driver construct (AsOX3545). Putative orthology of the Ae. aegypti AeAct4 and An. stephensi ASTM009772 genes was assigned by sequencing (Additional file 1: Figure S1) and reciprocal Blast analysis. Blastp using the predicted AeAct-4 protein sequence as query identified ASTM009772-PA as the best hit within the $A n$. stephensi proteome (E-value $=0.0$, Score $=2010$, Identity $=99.2 \%$ ). The reciprocal blast, using ASTM009772-PA as query identified AeAct-4 as the best hit within the Ae. aegypti proteome (E-value $=0.0$, Score $=2010$, Identity $=99.2 \%)$. The orthology assignment is supported further by gene expression analyses showing that in An. stephensi ASTM009772-RA transcripts are present in fourth instar larvae (mixed sexes) and female pupae, and absent in male pupae and adults, a pattern similar to that of AeAct-4 [2,6].

\section{Generation of transgenic driver lines}

A total of 1,423 An. stephensi embryos injected with the OX3545 driver construct and piggyBac helper plasmid 


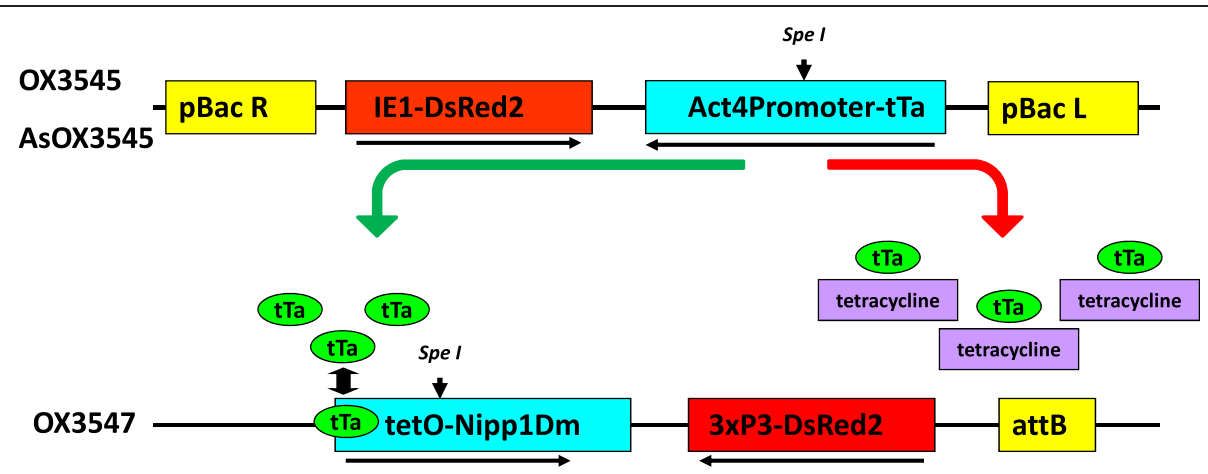

Figure 1 Schematic representations of the transformation constructs OX3545, AsOX3545 and OX3547, and the mechanism of action of the double transgene-based female-specific RIDL. OX3545 and OX3547 were previously described in detail [2]. AsOX3545 is a similar to OX3545, with the Anopheles stephensi Actin-4 regulatory sequences replacing the Aedes aegypti Actin-4 sequence. Actin 4 promoters (Act4P) drive the expression of the tetracycline-repressible transactivator protein (tTa) in the flight muscles of adult female mosquitoes. $\mathrm{tTA}$ binds tetO in the absence of tetracycline, driving expression of the effector molecule, Nuclear Inhibitor of PP1 (Nipp1Dm) [22,23], leading to disruption of normal cell functions. Tetracycline prevents tTa binding to tetO abolishing expression of Nipp1Dm. The positions of the Spel recognition and cleavage sites in OX3545, AsOX3545 and OX3547 are indicated by vertically oriented arrows. Horizontally oriented arrows indicate the direction of transcription for each component of the constructs. Abbreviations: pBac R and L, piggyBac right and left inverted repeats, respectively; attB, $\varphi$ C31 recombination site; DsRed2, red fluorescent protein open reading frame; IE1, baculovirus immediate-early gene promoter driving DsRed2 expressed throughout the body; $3 \times \mathrm{P} 3$, artificial promoter consisting of a multimer of the binding site (P3), driving high levels of expression in the eye.

resulted in 447 (31\%) individuals surviving and developing into adults. These $G_{0}$ adults were back-crossed with the wild-type, non-transgenic recipient strain and 31 produced DsRed2 fluorescent $G_{1}$ larvae for an estimated transformation efficiency of $\sim 7 \%$. All DsRed2 fluorescent progeny from 16 of the 31 outcrosses died during their pre-imago stages and hence adults were recovered from only 15 matings. These transgenic lines were designated DAa- $x x$, indicating that they are driver lines carrying a transgene with the Ae. aegypti Actin-4 regulatory sequence. Eight of the $\mathrm{G}_{1}$ driver lines (DAa-1, 2, 3, 4, 5, 6, 7 and 8) produced viable transgenic offspring when crossed with wild-type mosquitoes (Table 1). All driver lines derived from injections with the OX3545 construct exhibited some degree of lethality during metamorphosis of the $G_{2}$ mosquitoes, with line DAa-1 showing only $8 \%$ survival. Survival in line DAa-1 increased to $24 \%$ by the fifth generation $\left(G_{5}\right)$ post injection (Additional file 2: Table S1). All driver lines produced a higher percentage of adult males in generations $G_{2}$ through $G_{5}$ than was observed in control lines. Southern blot analyses of genomic DNA isolated from $G_{5}$ adult mosquitoes indicate distinct transgene integration events in each of the characterized lines (Figure 2). All lines had hybridization signal consistent with a single insertion of the driver construct in the An. stephensi genome.

The driver construct containing the An. stephensi Actin-4 regulatory DNA, AsOX3545, was injected in 995 embryos, resulting in 408 ( $41 \%$ survival) $\mathrm{G}_{0}$ adults. Twenty-one transgenic lines ( $\sim 5 \%$ transformation efficiency), designated DAs- $x x$, were generated after outcrossing $G_{0}$ adults with the wild-type strain (Table 2).
For one line, DAs-16, all transgenic females were flightless. This phenotype was not repressed by rearing on tetracycline. Southern blot analyses revealed a variable number of transgene insertions, ranging from one (lines DAs-28 and DAs-30) to at least four in line DAs-20 (Figure 2).

Table 1 Sex ratio and survival of driver transgenic lines carrying the Aedes aegypti Act-4 promoter (OX3545 construct)

\begin{tabular}{|c|c|c|c|c|c|}
\hline \multirow{3}{*}{$\begin{array}{l}\mathrm{G}_{0} \\
\text { Lines } \\
\text { outcrossed with } \\
\text { wild-type }\end{array}$} & \multirow{3}{*}{$\begin{array}{l}\mathrm{G}_{1} \\
\text { Transgenic } \\
\text { adults }\end{array}$} & \multicolumn{4}{|l|}{$\mathrm{G}_{2}$} \\
\hline & & \multirow{2}{*}{$\begin{array}{l}\text { Wild } \\
\text { type } \\
\text { larvae }\end{array}$} & \multirow[t]{2}{*}{$\begin{array}{l}\text { Transgenic } \\
\text { larvae }\end{array}$} & \multicolumn{2}{|c|}{$\begin{array}{l}\text { Transgenic } \\
\text { adults* }\end{array}$} \\
\hline & & & & Females & Males \\
\hline DAa-1 & 10 & 325 & 199 & 0 & 17 \\
\hline DAa-2 ô & 40 & 680 & 138 & 21 & 22 \\
\hline DAa-3 ठే & 10 & 200 & 86 & 3 & 29 \\
\hline DAa-4 ठ & 178 & 1140 & 659 & 31 & 134 \\
\hline DAa-5 万人 & 40 & 90 & 45 & 3 & 11 \\
\hline DAa-6 q & 10 & 70 & 44 & 22 & 9 \\
\hline DAa-7 q & 10 & 100 & 45 & 9 & 15 \\
\hline DAa-8 q & 10 & 90 & 30 & 10 & 17 \\
\hline DAa-9 ठ․ & 1 o, 2 우 & 0 & 0 & 0 & 0 \\
\hline DAa-10 ठ & 10 & 0 & 0 & 0 & 0 \\
\hline DAa-11 $\sigma^{\pi}$ & 20 & 0 & 0 & 0 & 0 \\
\hline DAa-12 & 10 & 0 & 0 & 0 & 0 \\
\hline DAa-13 ऊ̊ & 20 & 0 & 0 & 0 & 0 \\
\hline DAa-14 đ̂ & 10 & 0 & 0 & 0 & 0 \\
\hline 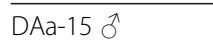 & 19 & 0 & 0 & 0 & 0 \\
\hline
\end{tabular}

${ }^{*}$ A flightless phenotype was not observed in males or females. An expanded Table showing results of five generations is provided as Additional file 2: Table S1. 


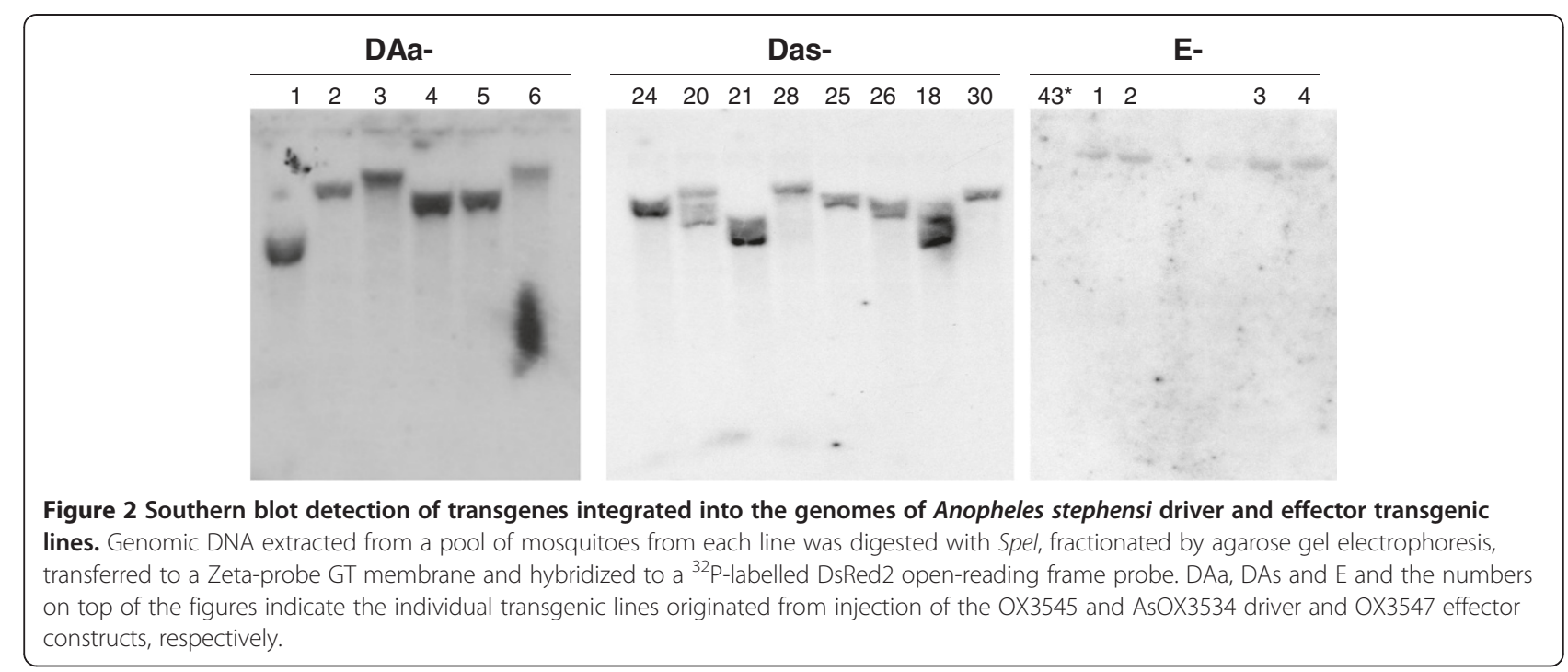

Table 2 Sex ratio, survival, and flightless phenotype of driver transgenic lines carrying the Anopheles stephensi Act-4 promoter (AsOX3545 construct)

\begin{tabular}{|c|c|c|c|c|c|}
\hline \multirow{4}{*}{$\begin{array}{l}\mathrm{G}_{0} \\
\text { Lines outcrossed } \\
\text { with wild-type }\end{array}$} & \multirow{4}{*}{$\begin{array}{l}\mathrm{G}_{1} \\
\text { Transgenic adults }\end{array}$} & \multicolumn{4}{|l|}{$\mathrm{G}_{2}$} \\
\hline & & \multirow[t]{3}{*}{ Wild-type larvae } & \multirow[t]{3}{*}{ Transgenic larvae } & \multicolumn{2}{|l|}{ Transgenic adults } \\
\hline & & & & Females & Males \\
\hline & & & & flightless/flying & flying \\
\hline DAs-16 & 10 & 120 & 119 & $33 / 0^{*}$ & 33 \\
\hline DAs-17 & $17 \AA$ & 300 & 101 & $4 / 21$ & 36 \\
\hline DAs-18 & 330 & 300 & 131 & $2 / 19$ & 51 \\
\hline DAs-19 & 10 & 210 & 129 & $0 / 53$ & 48 \\
\hline DAs-20 & 20 & 320 & 321 & $0 / 21$ & 65 \\
\hline DAs-21 & 40 & 510 & 202 & $0 / 37$ & 95 \\
\hline DAs-22 & 10 & 260 & 176 & $0 / 21$ & 48 \\
\hline DAs-23 & 10 & 170 & 147 & $0 / 19$ & 52 \\
\hline DAs-24 & 10 & 410 & 344 & $0 / 19$ & 32 \\
\hline DAs-25 & 14 万人 & 350 & 168 & $0 / 19$ & 35 \\
\hline DAs-26 & 27 గ & 400 & 107 & $0 / 29$ & 39 \\
\hline DAs-27 & 40 & 70 & 62 & $0 / 4$ & 20 \\
\hline DAs-28 & 10 & 130 & 163 & $0 / 3$ & 35 \\
\hline DAs-29 & 10 万 & 410 & 178 & $0 / 8$ & 17 \\
\hline DAs-30 & 10 & 120 & 144 & $0 / 9$ & 6 \\
\hline DAs-31 & 19 & 300 & 46 & $0 / 3$ & 3 \\
\hline DAs-32 & 19 & 500 & 32 & $0 / 4$ & 14 \\
\hline DAs-33 & 1 운 & 450 & 37 & $0 / 4$ & 3 \\
\hline DAs-34 & 20 & 90 & 54 & $0 / 0$ & 3 \\
\hline DAs-35 & 19 & 400 & 47 & $0 / 0$ & 6 \\
\hline DAs-36 & 30 & 40 & 13 & $0 / 0$ & 1 \\
\hline
\end{tabular}

*The flightless female phenotype of line DAs-16 is not rescued by tetracycline. 
Table 3 Sex-ratio and survival of effector transgenic lines carrying the OX3547 construct

\begin{tabular}{|c|c|c|c|c|c|}
\hline \multirow{3}{*}{$\begin{array}{l}\mathrm{G}_{0} \\
\text { Effector lines outcrossed } \\
\text { with wild-type }\end{array}$} & \multirow{3}{*}{$\begin{array}{l}\mathrm{G}_{1} \\
\text { Transgenic adults }\end{array}$} & \multicolumn{4}{|l|}{$\mathrm{G}_{2}$} \\
\hline & & \multirow[t]{2}{*}{ Outcross } & \multirow[t]{2}{*}{ Transgenic larvae } & \multicolumn{2}{|c|}{ Transgenic adults } \\
\hline & & & & Females & Males \\
\hline $\mathrm{E}-1(\overbrace{}^{1})$ & 0 ภ, 28 q & G1 $9 \times W T^{*} \hat{0}$ & 57 & 29 & 26 \\
\hline $\mathrm{E}-2\left(\mathrm{o}^{2}\right)$ & $0 \hat{0}, 42$ 웅 & G1 $q \times$ WT ô & 128 & 59 & 62 \\
\hline $\mathrm{E}-3($ () & 60,2 운 & G1 $3 \times$ WT $q$ & 81 & 76 & 0 \\
\hline $\mathrm{E}-4($ (P) & $25 \hat{0}, 26$ ㅇ & G1 $\lesssim \times W T q$ & 32 & 27 & 0 \\
\hline
\end{tabular}

${ }^{*} \mathrm{WT}$, wild-type.

\section{Generation of transgenic effector lines}

The An. stephensi transgenic line attP43 has two $\phi C 31$ attP docking sites in its genome [20]. Five hundred line attP43 embryos injected with the attB-3 $\times$ P3-DsRed2tetO-Nipp1Dm effector construct (OX3547) produced 178 (36\% survival) adult mosquitoes (Table 3). The surviving adults were reared as 11 male and eight female pools and out-crossed with wild-type mosquitoes. The progeny of four pools, designated E-1 to E-4, contained transgenic individuals detected by fluorescence microscopy. The sex ratio of the progeny is consistent with the inserted transgene being integrated into the $\mathrm{X}$ chromosome. Genomic DNA extracted from $G_{1}$ transgenic mosquitoes analyzed with Southern blots revealed that the effector transgene was inserted into the same Xlinked $\phi C 31$ attP docking site in all four integration events (Figure 2). Adults of the four transgenic lines were combined in a single population and named E-1.

\section{Crossings of DAa driver and E-1 effector lines}

Seven DAa driver lines (DAa1-7) were crossed with the effector line E-1 and the flight capabilities and sex ratio of their progeny analysed (Table 4). Larvae hemizygous for both driver and effector transgenes were identified by the

Table 4 Sex-ratio, survival, and flightless phenotypes in the F1 progeny of crosses between the effector line E-1 and driver lines engineered with either OX3545 (DAa-) or AsOX3545 (DAs-)

\begin{tabular}{|c|c|c|c|c|c|c|}
\hline \multirow{2}{*}{$\begin{array}{l}\sigma^{\top} \text { driver lines outcrossed } \\
\text { with the } Q \text { effector line E-1 }\end{array}$} & \multicolumn{2}{|l|}{ Larvae } & \multicolumn{4}{|c|}{ Transgenic adults } \\
\hline & $\begin{array}{l}\text { Only one } \\
\text { transgene }\end{array}$ & $\begin{array}{l}\text { Effector and } \\
\text { driver transgenes }\end{array}$ & Flying females & Flightless females & Flying males & $\begin{array}{l}\text { Totals } \\
\text { (\% survival larvae-adult) }\end{array}$ \\
\hline DAa-1 & 775 & 144 & 0 & 1 & 62 & $63(44 \%)$ \\
\hline DAa-2 & 1150 & 307 & 7 & 0 & 34 & 41 (13\%) \\
\hline DAa-3 & 4340 & 880 & 9 & 172 & 345 & $517(70 \%)$ \\
\hline DAa-4 & 600 & 110 & 3 & 23 & 29 & $54(49 \%)$ \\
\hline DAa-5 & 900 & 226 & 47 & 0 & 96 & $143(63 \%)$ \\
\hline DAa-6 & 1830 & 371 & 140 & 0 & 143 & $283(76 \%)$ \\
\hline DAa-7 & 1200 & 239 & 41 & 6 & 74 & $121(51 \%)$ \\
\hline DAs-17 & nd & 465 & 80 & 79 & 177 & $336(72 \%)$ \\
\hline DAs-18 & nd & 89 & 11 & 3 & 23 & $37(41 \%)$ \\
\hline DAs-19 & nd & 185 & 58 & 20 & 62 & $140(75 \%)$ \\
\hline DAs-20 & nd & 152 & 11 & 0 & 52 & $63(41 \%)$ \\
\hline DAs $-21^{*}$ & nd & 1545 & 0 & 161 & 483 & $644(42 \%)$ \\
\hline DAs-22 & nd & 1483 & 3 & 397 & $507(1)^{* *}$ & 907 (61\%) \\
\hline DAs-24 & nd & 93 & 23 & 4 & 28 & $55(59 \%)$ \\
\hline DAs-25* & nd & 761 & 0 & 70 & 193 & $263(35 \%)$ \\
\hline DAs-26 & nd & 328 & 15 & 86 & 112 & $213(65 \%)$ \\
\hline DAs-28 & nd & 244 & 19 & 0 & 73 & $92(37 \%)$ \\
\hline DAs-29 & nd & 107 & 33 & 0 & 33 & $66(61 \%)$ \\
\hline DAs-30 & nd & 226 & 15 & 0 & 14 & $29(12 \%)$ \\
\hline DAs-34 & nd & 114 & 8 & 0 & 0 & $8(0 \%)$ \\
\hline DAs-36 & nd & 267 & 21 & 0 & 46 & 67 (25\%) \\
\hline
\end{tabular}

*Lines with design-feature phenotypes.

**Crossing Das-22 and E-1 lines generated one flightless male (indicated in parenthesis). 


\begin{tabular}{|c|c|c|c|c|c|c|c|}
\hline \multirow{2}{*}{$\begin{array}{l}\sigma^{7} \text { driver lines outcrossed } \\
\text { with } \$ \text { effector line E-1 }\end{array}$} & \multirow{2}{*}{$\begin{array}{l}\text { Tetracycline } \\
\text { concentration }\end{array}$} & \multicolumn{2}{|l|}{ Larvae } & \multicolumn{4}{|c|}{ Transgenic adults } \\
\hline & & $\begin{array}{l}\text { Only one } \\
\text { transgene }\end{array}$ & $\begin{array}{l}\text { Effector + driver } \\
\text { transgenes }\end{array}$ & $\begin{array}{l}\text { Flying } \\
\text { females }\end{array}$ & $\begin{array}{l}\text { Flightless } \\
\text { females }\end{array}$ & $\begin{array}{l}\text { Flying } \\
\text { males }\end{array}$ & $\begin{array}{l}\text { Totals } \\
\text { (\% survival larvae-adult) }\end{array}$ \\
\hline DAa-3 & $10 \mu \mathrm{g} / \mathrm{ml}$ & 2535 & 371 & 108 & 16 & 226 & $350(94 \%)$ \\
\hline DAa-3 & $5 \mu \mathrm{g} / \mathrm{ml}$ & 930 & 269 & 37 & 3 & 91 & 131 (49\%) \\
\hline DAa-3 & $1 \mu \mathrm{g} / \mathrm{ml}$ & 610 & 143 & 21 & 10 & 69 & $100(70 \%)$ \\
\hline DAa-3 & 100 ng/ml & 750 & 162 & 15 & 16 & 61 & 92 (57\%) \\
\hline DAa-3 & $10 \mathrm{ng} / \mathrm{ml}$ & 600 & 127 & 9 & 28 & 38 & 75 (59\%) \\
\hline DAs-21 & $10 \mu \mathrm{g} / \mathrm{ml}$ & nd & 233 & 25 & 18 & 82 & $125(54 \%)$ \\
\hline DAs-22 & $10 \mu \mathrm{g} / \mathrm{ml}$ & nd & 628 & 155 & 12 & $285(1)^{*}$ & $453(72 \%)$ \\
\hline
\end{tabular}

*One flightless male was observed among the progeny of driver DAs-22 $\hat{\alpha} \mathrm{x}$ effector $\mathrm{E}-1$ \% cross (indicated in parenthesis).

tissue-specific expression patterns of DsRed2 fluorescence consistent with those produced by the $3 \times \mathrm{P} 3$ and the IE1 promoters (Additional file 3: Figure S2).

Larvae carrying both the effector and the driver transgenes are expected to represent $25 \%$ of the progeny. $X^{2}$ analyses of crosses between males from DAa lines and E-1 females resulted in significantly reduced proportions of double-hemizygous larvae relative to this expectation ( $X^{2}$ from 11.79 to $184.11 ; \mathrm{df}=1$, and $\mathrm{p}<0.001$ for all crosses). These results support the interpretation that some load is associated with carrying the transgenes. The surviving double-hemizygous individuals were maintained in the absence of tetracycline and allowed to develop into adults. Crosses with driver line DAa-1 produced $97 \%$ adult male progeny, reflecting significant lethality in developing females. The single adult female recovered from this cross exhibited a flightless phenotype. In contrast, crosses with driver line DAa-6 males resulted in equal numbers of adults of both sexes and no flightless phenotypes were observed among the surviving females. In addition, the flightless phenotype was not observed in any female of crosses involving males from DAa-5 or DAa-2. Driver lines DAa-3 and DAa- 4 crossed with E-1 produced results consistent with the design intent of the transgenes with $95 \%$ of the females exhibiting the flightless phenotype and all males capable of flight.

\section{Crossings of DAs driver and E-1 effector lines}

Eight of 14 DAs driver lines produced progeny with a flightless-female phenotype following crossing with the effector line E-1 (Table 4). The majority of the female progeny of lines DAs-24 (15\% flightless) and DAs-18 (21\% flightless) was able to fly. Line DAs-17 produced similar numbers of flying and flightless females. Lines DAs-26 and DAs-22 produced mostly flightless females (85\% and 99\% flightless, respectively) while DAs-21 and DAs-25 crosses with E-1 resulted in 100\% flightless females. The sex-ratios of the adult progeny resulting from DAs-21, DAs-25 and DAs-22 crosses with E-1 are abnormal $\left(X^{2}\right.$ from 13 to 160 ; $\mathrm{df}=1$, and $\mathrm{p}<0.001$ for all crosses) with more males than females indicating some degree of female lethality at the sub adult stages. No sex-associated lethality was observed when crossing lines DAs-24, DAs-26, DAs17 and DAs-19 ( $X^{2}$ from 0.0 to $0.9 ; \mathrm{df}=1$, and $\mathrm{p}>0.2$ for all crosses).

\section{Tetracycline suppression of the flightless phenotype}

Tetracycline provided to double-hemizygous transgenic An. stephensi is expected to rescue the flightless-female phenotype by preventing tTA binding to tetO and therefore inhibiting expression of the effector molecule Nipp1Dm. Eggs (estivated embryos) were collected from E-1 females mated with DAa-3, DAs-21 or DAs-22 driver line males and allowed to develop either in the presence or absence of tetracycline (Tables 4 and 5). The presence of tetracycline results in adults of both sexes with the flying, wild-type phenotype. All adult males except one could fly independent of the presence of tetracycline. In contrast, 98\% (731/743 combined for DAa-3, DAs-21 and DAs-22; Table 4) of the adult females reared in the absence of tetracycline were flightless. The majority, $\geq 67 \%$, of the females treated with $\geq 1 \mu \mathrm{g} / \mathrm{ml}$ tetracycline were able to fly, while tetracycline concentrations of 100 and $10 \mathrm{ng} / \mathrm{ml}$ only rescued partially (48 and $24 \%$, respectively) the flightless phenotype (Table 5).

\section{Conclusions}

The results shown here demonstrate that the genetics and resulting phenotypes of a female-specific RIDL strategy, previously developed for dengue vector mosquitoes $[2,4]$ can be adapted to a vector of human malaria, $A n$. stephensi. This demonstration supports efforts to optimize the efficacy of the gene constructs and to eventually perform cage and field trials to assess the usefulness of this approach as a malaria vector population suppression tool.

It is clear that further refinements of this system are required. Efficient scale-up would benefit from having to manage only a single line, so linkage of the driver and 
effector genes would ultimately be required. Furthermore, piggyBac-mediated transposition was used to insert randomly the driver constructs into the mosquito genome. The expectation was that position effects resulting from the activity state of the DNA surrounding each independent insertion site would influence in a variable manner the expression of the driver construct. This was evident in variable penetrance of the intended flightless phenotype and the sex-independent and -dependent lethality in some lines. Remarkably, Southern blot analyses showed that all of the recovered driver lines carrying the AeAct-4 promoter and at least two of those carrying the AsAct-4 promoter had single transgene insertions. This is unusual for piggyBac integration into An. stephensi [20,24] and supports the conclusion that the driver construct alone can be deleterious if present in high-copy number as well as being integrated at a chromosomal site that enhances its expression. Selection and characterization of favourable chromosomal docking sites, site-specific recombination and DNA fragments with insulator-like activity would assist the development of a strain with the optimized flightless phenotype and diminish or eliminate male fitness impact [20,24,25].

Scale-up in testing of novel genetic strains is needed to ensure that the engineered mosquitoes function as designed in the field. The Ae aegypti fsRIDL line OX3604C had outstanding performance characteristics in small and large laboratory cage trials, but did not meet efficiency expectations derived from modelling when tested in large outdoor field cages $[7,8]$. It is important to note that the field-cage trials were limited to only one test of a single, independently-derived fsRIDL strain. Here again, strain optimization using alternative characterized genome insertion sites, DNA insulator sequences [24] and even redesigning the transgenes could produce a strain that can be used with the expectation of an epidemiological impact on pathogen transmission.

The translation of new technologies from the laboratory to the field requires that resulting products function in a safe and efficacious manner. Transgenic mosquito technologies bring with them a number of challenges that can be addressed in the design features of the final products and site-specific community engagement activities [26-28]. A specific concern about the conditional, dominant, lethal genes is whether environmental contamination by tetracycline could produce a hazard by rescuing the flightless phenotype in the released transgenic mosquitoes. The most plausible source of rescue would be tetracycline contaminating larval habitats. No reports exist of measurements of tetracycline in the urban breeding sites of An. stephensi. However, there is an extensive literature on the widespread use of antibiotics for therapeutic, prophylactic and growth promotion purposes in livestock production. Antibiotics, including tetracycline and its analogues, are transferred to soils and surface waters when manure from the animals is spread on farmland or held in wastewater ponds. Several studies have been conducted to measure the concentrations of antibiotics in wastewater, animal waste and soil from manure-treated farmland. In studied sites, concentrations of tetracycline, tetracycline analogues or tetracycline degradation products were found to be lower than $1 \mu \mathrm{g} / \mathrm{ml}$. One of the highest numbers measured was $0.698 \mathrm{ng} / \mathrm{ml}$ tetracycline in farmland treated with pig-manure slurry [29]. Other locations, such as waste-water treatment facilities, where persistent tetracycline could come from various sources such as cities and rural areas, had a maximum tetracycline concentration of $0.004 \mu \mathrm{g} / \mathrm{ml}$ [30]. The highest detected concentration of chlortetracycline in the same study was estimated at $0.0012 \mu \mathrm{g} / \mathrm{ml}$. These concentrations are atypical, though. Bodies of water such as rivers and streams where runoff from farms could potentially be problematic contained minimal amounts of tetracycline, with concentrations below the limit of detection $(\leq 0.5 \mathrm{ng} / \mathrm{ml})$ [31]. Reviews examining tetracycline levels measured in waste-water treatment plants in USA and Asia found concentrations in the range $<0.00003-0.62 \mathrm{ng} / \mathrm{ml}[32,33]$. These data indicate that environmental tetracycline (and tetracycline analogue) concentrations detected in the breeding sites in which An. stephensi larvae are most likely to be located are not sufficient to rescue the engineered mosquito flightless phenotype.

Anopheles stephensi is an important malaria vector in the Indian subcontinent. Therefore the management of An. stephensi populations is of prime importance to public health and welfare. Successful population suppression could result in local or regional vector elimination dependent on the scope and size of the effort. It is anticipated that this suppression would result in less parasite transmission and therefore reduced human morbidity and mortality. However, population suppression technologies would have to be sustained to prevent re-colonization of the treated areas following vector migration or natural- or human-aided dispersal. Sustainable transgenic technologies also are being developed and these may represent second-generation genetic tools for controlling parasite transmission [25]. In the interim, the data presented here support the conclusion that fsRIDL should be developed as a tool in integrated pest management practices to control malaria transmission in urban settings were An. stephensi is the major vector.

\section{Additional files}

Additional file 1: Figure S1. Primary nucleic acid sequence and schematic representation of the Anopheles stephensi Actin-4 gene. A) Capitalized nucleotide sequences correspond to exons 1 and 2, 
96 and $1155 \mathrm{nt}$ in length, respectively, while lower case indicates the 1012 nt $5^{\prime}$-end flanking sequence and the 271 nt intron. Underlined sequences indicate the locations of primers described in the manuscript and the transcription $(+1)$ and translation (ATG) start sites are indicated underlined and in bold. B) Exons 1 and 2 (red boxes), the $5^{\prime}$ flanking sequence (green box) and the intron (yellow box) of the An. stephensi Actin-4 gene. Lines underneath indicate the positions of the $1400 \mathrm{nt}$ long AsActin4 regulatory region used to generate AsOX3545, the 5' RACE product that identified the transcription start-site and the RT-PCR product utilized to determine the gene expression profile. C) Gene amplification analysis of the expression profile of AsAct-4. The $536 \mathrm{nt}$ amplicon is specific for the gene product. Template mRNA samples were derived from larvae (L), pupae (P) and adults (A). An amplification product specific to the 18s rRNA is the positive sample control.

Additional file 2: Table S1. Sex ratio and survival of Anopheles stephensi driver transgenic lines (DAa-) carrying the construct OX3545.

Additional file 3: Figure S2. Anopheles stephensi larvae hemizygous for driver and/or effector transgenes were identified by patterns of DsRed2 fluorescence consistent with those produced by the 3XP3 and the IE1 promoters. DAa-3 larvae display a scattered fluorescence pattern throughout the body driven by the IE1 promoter (A) while DsRed2 expression in the effector line $\mathrm{E}-1$ is driven by the eye-specific promoter 3XP3 (B). Larvae hemizygous for both driver and effector transgenes (C) were identified by patterns of DsRed2 fluorescence in their eyes and bodies. Wild-type (WT) shows the fluorescence background of wild type non-transgenic An. stephensi larvae.

\section{Competing interests}

Those authors affiliated to Oxitec Limited (SS, GF and LA) are employees of this company, which provided salary and other support for the research programme. Such employees may have shares or share options in Oxitec Ltd. Both Oxitec Ltd and Oxford University have one or more patents or patent applications related to the subject of this paper.

\section{Authors' contributions}

$\mathrm{OM}, \mathrm{NJ}, \mathrm{LA}, \mathrm{DMB}$, and $\mathrm{AAJ}$ were involved in the conceptualization, research design, data collection and preparation of the manuscript. AF, SS, GF, SM, and KC contributed to reagent development and data collection. All authors read and approved the final manuscript.

\section{Acknowledgments}

We thank Karen Chu and Judy Coleman for mosquito care and for the DsRed2 phenotype images, and Neil Morrison for reviewing the manuscript. This research was funded by a grant to the Regents of the University of California from the Foundation for the National Institutes of Health through the Grand Challenges in Global Health initiative.

\section{Author details}

'Department of Molecular Biology \& Biochemistry, University of California, Irvine, CA, 92697-3900, USA. ${ }^{2}$ Oxitec Ltd, 71 Milton Park, Abingdon, Oxfordshire, OX14 4RX, UK. ${ }^{3}$ Departments of Microbiology \& Molecular Genetics and Molecular Biology \& Biochemistry, 3205 McGaugh Hall, University of California, Irvine, CA, 92697-3900, USA. ${ }^{4}$ Department of Zoology, University of Oxford, South Parks Road, Oxford OX1 3PS, UK.

Received: 4 March 2013 Accepted: 19 April 2013

Published: 26 April 2013

\section{References}

1. Thomas DD, Donnelly CA, Wood RJ, Alphey LS: Insect population control using a dominant, repressible, lethal genetic system. Science 2010, 287:2474-2476.

2. Fu G, Lees RS, Nimmo D, Aw D, Jin L, Gray P, Berendonk TU, White-Cooper H, Scaife S, Kim Phuc H, Marinotti O, Jasinskiene N, James AA, Alphey L: Female-specific flightless phenotype for mosquito control. Proc Natl Acad Sci U S A 2010, 107:4550-4554.

3. Black WC 4th, Alphey L, James AA: Why RIDL is not SIT. Trends Parasitol 2011, 27:362-370.
4. Labbé GM, Scaife S, Morgan SA, Curtis ZH, Alphey L: Female-specific flightless (fsRIDL) phenotype for control of Aedes albopictus. PLoS Negl Trop Dis 2012, 6:e1724.

5. Alphey L, Benedict M, Bellini R, Clark GG, Dame DA, Service MW, Dobson SL: Sterile-insect methods for control of mosquito-borne diseases: an analysis. Vector Borne Zoonotic Dis 2010, 10:295-311.

6. Muñoz D, Jimenez A, Marinotti O, James AA: The AeAct-4 gene is expressed in the developing flight muscles of female Aedes aegypti. Insect Mol Biol 2004, 13:563-568.

7. Wise de Valdez MR, Nimmo D, Betz J, Gong HF, James AA, Alphey L, Black WC 4th: Genetic elimination of dengue vector mosquitoes. Proc Natl Acad Sci U S A 2011, 108:4772-4775.

8. Facchinelli L, Valerio L, Ramsey JM, Gould F, Walsh RK, Bond G, Robert MA, Lloyd AL, James AA, Alphey L, Scott TW: Field cage studies and progressive evaluation of genetically-engineered mosquitoes. PLoS Negl Trop Dis 2013, 7:e2001.

9. Sharma VP: Hidden burden of malaria in Indian women. Malar J 2009, 8:281.

10. Hay SI, Sinka ME, Okara RM, Kabaria CW, Mbithi PM, Tago CC, Benz D, Gething PW, Howes RE, Patil AP, Temperley WH, Bangs MJ, Chareonviriyaphap T, Elyazar IR, Harbach RE, Hemingway J, Manguin S, Mbogo CM, Rubio-Palis Y, Godfray H: Developing global maps of the dominant anopheles vectors of human malaria. PLOS Med 2010, 7:e1000209.

11. Qi Q, Guerra CA, Moyes CL, Elyazar IR, Gething PW, Hay SI, Tatem AJ: The effects of urbanization on global Plasmodium vivax malaria transmission. Malar J 2012, 11:403.

12. WHO: World malaria report. Geneva: World Health Organization; 2009.

13. Oshaghi MA, Yaaghoobi F, Abaie MR: Pattern of mitochondrial DNA variation between and within Anopheles stephensi (Diptera: Culicidae) biological forms suggests extensive gene flow. Acta Trop 2006, 99:226-233.

14. Gakhar SK, Sharma R, Sharma A: Population genetic structure of malaria vector Anopheles stephensi Liston (Diptera: Culicidae). Ind J Exp Biol 2013, 51:273-279.

15. Vectorbase: vectorbase.org

16. Handler AM, Harrell RA 2nd: Germline transformation of Drosophila melanogaster with the piggyBac transposon vector. Insect Mol Biol 1999, 8:449-457.

17. Isaacs AT, Li F, Jasinskiene $N$, Chen X, Nirmala X, Marinotti O, Vinetz JM, James AA: Engineered resistance to Plasmodium falciparum development in transgenic Anopheles stephensi. PLoS Pathog 2011, 7:e1002017.

18. Mathur G, Sanchez-Vargas I, Alvarez D, Olson KE, Marinotti O, James AA: Transgene-mediated suppression of dengue viruses in the salivary glands of the yellow fever mosquito, Aedes aegypti. Insect Mol Biol 2010, 19:753-763.

19. Sambrook J, Fritsch EF, Maniatis T: Molecular cloning. A laboratory manual. New York: Plainview: Cold Spring Harbor Laboratory Press; 1989.

20. Amenya DA, Bonizzoni M, Isaacs AT, Jasinskiene N, Chen H, Marinotti O, Yan G, James AA: Comparative fitness assessment of Anopheles stephensi transgenic lines receptive to site-specific integration. Insect Mol Biol 2010, 19:263-269

21. Nimmo DD, Alphey L, Meredith JM, Eggleston P: High efficiency site-specific genetic engineering of the mosquito genome. Insect Mol Biol 2006, 15:129-136

22. Bennett D, Szoor B, Gross S, Vereshchagina N, Alphey L: Ectopic expression of inhibitors of Protein Phosphatase type 1 (PP1) can be used to analyse roles of PP1 in Drosophila development. Genetics 2003, 164:235-245.

23. Parker L, Gross S, Beullens M, Bollen M, Bennett D, Alphey L: Functional interaction between NIPP1 and PP1 in Drosophila: lethality of overexpression of NIPP1 in flies and rescue by the over-expression of PP1. Biochem J 2002, 368:789-797.

24. Carballar-Lejarazú R, Jasinskiene N, James AA: Exogenous gypsy insulator sequences modulate transgene expression in the malaria vector mosquito, Anopheles stephensi. Proc Natl Acad Sci U S A. 110:7176-7181

25. Isaacs AT, Jasinskiene N, Tretiakov M, Thiery I, Zettor A, Bourgouin C, James AA: Transgenic Anopheles stephensi coexpressing single-chain antibodies resist Plasmodium falciparum development. Proc Natl Acad Sci U S A 2012, 109:E1922-E1930.

26. Lavery JV, Tinadana PO, Scott TW, Harrington LC, Ramsey JM, Ytuarte-Nuñez C, James AA: Towards a framework for community engagement in global health research. Trends Parasitol 2010, 26:279-283. 
27. World Health Organization: Progress and prospects for the use of geneticallymodified mosquitoes to inhibit disease transmission. Report on planning meeting 1: Technical consultation on current status and planning for future development of genetically-modified mosquitoes for malaria and dengue control. Geneva, Switzerland: WHO; 2010:64.

28. The malERA Consultative Group on Vector Control, Alonso PL, Besansky NJ, Burkot TR, Collins FH, Hemingway J, James AA, Lengeler C, Lindsay S, Liu Q, Lobo NF, Mnzava A, Tanner M, Zwiebel L: A research agenda for malaria eradication: vector control. PLoS Med 2011, 8:e1000401.

29. Beausse J: Selected drugs in solid matrices: a review of environmental determination, occurrence and properties of principal substances. Trends Anal Chem 2004, 23:753-761.

30. Karthikeyan K, Bleam WF: Occurrence of antibiotics in wastewater effluents and their mobility in soils: a case study for Wisconsin. http://digital.library.wisc.edu/1711.dl/EcoNatRes.KarthikeyanOccurr.

31. Campagnolo ER, Johnson KR, Karpati A, Rubin CS, Kolpin DW, Meyer MT, Esteban JE, Currier RW, Smith K, Thu KM, McGeehin M: Antimicrobial residues in animal waste and water resources proximal to large-scale swine and poultry feeding operations. Sci Total Environ 2002, 299:89-95.

32. Gulkowska A, He Y, So MK, Yeung LW, Leung HW, Giesy JP, Lam PK, Martin $M$, Richardson BJ: The occurrence of selected antibiotics in Hong Kong coastal waters. Mar Pollut Bull 2007, 54:1287-1293.

33. Le-Minh N, Khan SJ, Drewes JE, Stuetz RM: Fate of antibiotics during municipal water recycling treatment processes. Water Research 2010 44:4295-4323.

doi:10.1186/1475-2875-12-142

Cite this article as: Marinotti et al.: Development of a population

suppression strain of the human malaria vector mosquito, Anopheles stephensi. Malaria Journal 2013 12:142.

\section{Submit your next manuscript to BioMed Central and take full advantage of:}

- Convenient online submission

- Thorough peer review

- No space constraints or color figure charges

- Immediate publication on acceptance

- Inclusion in PubMed, CAS, Scopus and Google Scholar

- Research which is freely available for redistribution 